\title{
O CEFAM E A FORMAÇÃO INICIAL DE UMA GERAÇÃO DE PROFESSORES
}

\section{CEFAM AND THE INITIAL TRAINING OF A GENERATION OF TEACHERS}

\author{
Diego Moreira ${ }^{12}$
}

\section{RESUMO}

O artigo apresenta a trajetória de formação e profissionalização dos egressos do CEFAM (Centros Específicos de Formação e Aperfeiçoamento para o Magistério), numa leitura pessoal da história de vida e percurso formativo. Retoma momentos da vida e conecta com a história do magistério e do movimento de fundação do CEFAM no Brasil e em São Paulo.

Palavras-Chave: CEFAM. Magistério. Trajetórias. Profissionalização.

\section{INTRODUÇÃO}

O artigo versa sobre a trajetória de formação e profissionalização a partir do ingresso no magistério do CEFAM (Centro Específico de Formação e Aperfeiçoamento para o Magistério).

Ingressar no curso do magistério aos treze anos de idade e experimentar uma formação integral por quatro anos no período da adolescência, foi um percurso definidor para a vida. Compreender esse processo de formação e como a escola era organizada para entregar para a sociedade os profissionais da educação que atendessem todas as expectativas e demandas da população.

Num relato de vida, o texto procura apresentar como as políticas educacionais são importantes para que jovens se profissionalizem e tenham condições de permanecer na escola, bem como, a relevância de um projeto pedagógico lúcido e definido faz diferença para formar professores.

E conclui sobre as marcas dessa escola na vida e na profissionalização, na constituição da própria identidade e visão de mundo. A escola que me formou professor e a escola que me acolheu como profissional foram definidoras da minha história.

${ }^{12}$ Doutorando e Mestre em Educação pela PUCSP. Graduado em História e Pedagogia. Há mais de 20 anos atua na carreira docente, com experiência desde o ensino fundamental até a Pós Graduação, em redes públicas e privadas. É pesquisador na área de formação de professores e Gestores. Leciona na Pós graduacão nas áreas de Educacão e Gestão de Pessoas. 


\section{O VESTIBULINHO PARA O INGRESSO NO CURSO DE MAGISTÉRIO}

Ingressei no magistério sem ter clareza sobre o que significava fazer um curso de ensino médio numa escola chamada CEFAM.

Morador da zona leste da capital paulista, filho de pais trabalhadores que não tiveram acesso ao ensino superior, sempre fui estudante de escola pública estadual e lá pelos idos de 1996 cursava a $8^{\text {a }}$ série do ensino fundamental na E. E. Caetano Zamitti Mammana e concomitantemente fazia um cursinho preparatório para o vestibulinho, fortemente estimulado pelos meus pais para tentar ingressar nas escolas técnicas paulistas ou na tão disputada escola técnica federal.

A partir da indicação de alguns professores, os amigos da turma me chamaram para fazer inscrição para um vestibulinho numa escola de magistério em São Miguel Paulista. Não sabiam me explicar direito sobre o curso, mas estavam empolgados em razão de uma bolsa de estudos que poderiam receber.

Marcamos para uma tarde logo após a saída das aulas e percorremos cerca de cinco quilômetros a pé até a E. E. Eng ${ }^{\circ}$ Hugo Takahashi - CEFAM II para realizar a inscrição. Dentre os oito ou nove amigos da turma que realizaram a prova, apenas uma amiga e eu fomos classificados para a matrícula.

Eram disponibilizadas 120 vagas para o ingresso no primeiro ano do Ensino Médio e especialmente no vestibulinho de 1996 foram realizadas mais de 1400 inscrições para a prova.

Considerando as outras possibilidades de curso e distância para as escolas no centro da cidade de São Paulo, optei por cursar o magistério do CEFAM no bairro de São Miguel Paulista, que era a opção mais próxima da minha casa.

Reitero, não tinha clareza sobre o que significava uma escola de magistério de período integral. Só tínhamos as informações dadas pelos professores que era uma ótima escola.

\section{O COTIDIANO NO CEFAM}

O ingresso no primeiro ano do ensino médio era marcado por uma reunião que a coordenadora pedagógica conduzia junto com corpo docente e direção. No pátio da 
escola a presença de todos os responsáveis pelos estudantes era obrigatória e possuía um clima de tensão diante de tanta novidade se avizinhava.

As orientações burocráticas sobre a matrícula, o recebimento da bolsa de estudos e a rotina escolar eram passadas com grande formalidade, a reunião era sisuda e bem institucional. A coordenadora pedagógica sempre muito enfática e rigorosa fazia questão de deixar claro o que significava ingressar naquela escola e do compromisso que os ingressantes precisavam ter com a carreira. Os aprovados que não desejavam ser professores eram estimulados abertamente a não realizar a matrícula sob o risco da devolução dos valores recebidos nas bolsas de estudos.

Lembro de retornar para casa conversando com a minha mãe sobre o rigor e o comprometimento de estudos que a escola exigiria. Muitos documentos assinados, muitas recomendações de comportamento e claro, um mundo novo que se abria ao iniciar as aulas. Uniforme, alimentação, carteira de estudante, transporte, horários...cada detalhe que o período exigiria.

Para além das dinâmicas institucionais e do rigor técnico da gestão, o dia a dia do CEFAM nos apresentava mais cores e momentos de construção de muitos afetos. Já no primeiro mês de aula descobrimos como o funcionamento da escola acontecia na manutenção do "status-quo" interno. Uma dinâmica de organização já estabelecida e que não estava escrita em nenhum regimento interno.

Os $4^{\circ}$ anos do curso eram as turmas admiradas e exemplos a ser seguidos. Algumas alunas já faziam faculdade no período noturno e estágios durante o dia, assim tinham horários mais flexíveis e gozavam de alguns acessos e privilégios que os demais ainda não possuíam. Os temas sobre vestibulares e concursos rondavam as conversas delas.

Já pareciam professoras, andavam com muitos livros e estavam sempre estudando. Também tinham os times mais fortes nos campeonatos esportivos. Para um menino com treze anos de idade, aquelas eram as garotas mais bonitas e inalcançáveis do colégio.

Os $3^{\circ}$ anos eram os aspirantes ao modo de vida do $4^{\circ}$ ano, contudo ainda não gozavam dos mesmos privilégios. As tradicionais festas da escola eram organizadas pelas turmas dos terceiros anos, sendo assim, todo o trabalho de organização que os estudantes estavam envolvidos passava essencialmente pela capacidade de articulação 
desta série. As feiras, seminários e festas eram o passaporte para os privilégios na série seguinte.

Os $2^{\circ}$ anos eram os responsáveis pelas apresentações, decoração e organização da cozinha. Os eventos eram todos decorados sob a orientação e encomenda dos $3^{\circ}$ anos. Claro que sob o olhar crítico e avaliativo dos $4^{\circ}$ anos.

Aos $1^{\circ}$ anos ficava a parte de organização de cadeiras e limpeza. Toda a limpeza dos eventos era de nossa responsabilidade.

Não sei quem inventou essa divisão, ocorre que ela funcionava bem, mesmo com muitos questionamentos da hierarquia o grupo de docentes defendia esse modelo, no entanto, nas organizações estudantis como o grêmio e os campeonatos esportivos a divisão de classes (sem trocadilhos marxistas) era amplamente posta à prova.

O clima escolar era muito acolhedor, mesmo com carga horária grande, os docentes mantinham posturas de rigidez e acolhimento. Algumas aulas possuíam dinamismos que nunca tínhamos experimentado anteriormente e a vivência diária por muitas horas estimulava apoios e amizades verdadeiras.

O CEFAM de São Miguel possui 10 salas de aulas e entre 1995 até seu encerramento em 2005 ficou no prédio da E.E. Eng ${ }^{\circ}$ Hugo Takahashi. A estadia do CEFAM funcionava como um empréstimo da escola, pois em São Paulo o projeto nunca teve prédio próprio. Com cerca de 400 estudantes, a maioria esmagadora era de meninas. Entre 1997 e 2000 éramos 18 meninos nesse universo feminino.

O dia a dia do magistério era bem puxado, fazíamos 10 aulas diárias, entramos na escola às $07 \mathrm{~h}$ e saímos às $17 \mathrm{~h} 40$ minutos. O currículo era organizado em parte comum com as disciplinas do ensino médio e parte específica com as disciplinas do magistério. O curso possuía 4.000 horas somadas mais 720 horas de estágios supervisionados.

No primeiro ano do curso além das disciplinas de núcleo comum tínhamos disciplinas como História da Educação, Sociologia da Educação, Psicologia da Educação e Filosofia da Educação que pertenciam ao currículo específico do magistério. Este destaque ajuda a nos dar pistas para entender como essa geração de professores foi formada lendo autores densos desde muito cedo. Com idades entre treze, catorze e quinze anos, tínhamos contato com textos de Paulo Freire, Saviani, Chauí, Milton Santos entre outros. 
Até hoje guardo um exemplar de Pedagogia da Autonomia que ganhei no segundo semestre de 1997, imagina que tinha acabado de completar catorze anos. Isso aconteceu com toda a geração de professores que cursou o magistério no CEFAM.

Mesmo com as limitações naturais da maturidade, era nos dado acesso aos escritos de Wallon, Vygotsky e Piaget e discussões acaloradas sobre os rumos da política nacional. Lembro que no final do $1^{\circ}$ ano discutimos os textos de Marx com a turma de amigos que estavam nas séries posteriores.

O dia a dia no CEFAM não deixava dúvida sobre a formação para o exercício da profissão docente. Toda a organização da rotina distribuída em todas as séries essa finalidade era explícita e inquestionável.

No segundo ano do magistério eram iniciados os estágios de observação. E neste momento o conhecimento adquirido no primeiro ano do curso servia de base para os debates nas aulas pós estágio. Para os estágios também era exigido uma excelente postura profissional, de modo que o comportamento dos estagiários nas escolas parceiras que nos recebiam devia manter sempre postura correta de acordo com as orientações recebidas pelas professoras.

Por mais que a estrutura fosse adaptada para o curso integral, o cotidiano na escola de magistério possuía peculiaridades da vida comum, como a organização dos banheiros e da alimentação.

A maioria dos estudantes levava marmita para se alimentar e nem sempre a estrutura reservada para esse momento atendia o conjunto de mais de 400 alunos, dessa forma, constantes manifestações, reclamações e até um dia que decidimos realizar uma paralisação das aulas para exigir a melhoria das condições de permanência na escola.

O terceiro ano do curso era permeado pelas questões dos estágios, das aulas de metodologia de ensino e pelo vestibular. Intensos estímulos eram feitos pelos docentes para que todos se comprometessem na continuidade de estudos na universidade, de preferência pública.

As aulas de metodologia de ensino eram leves e bem dinâmicas, lembro que tínhamos professoras que já estavam concluindo o mestrado e todas possuíam ampla experiência com a alfabetização.

Naquele tempo, para nossa geração de professores o grande tema da formação eram os processos de alfabetização, a educação infantil ainda não fazia parte da 
secretaria de educação, e o desafio formativo do CEFAM era formar bons alfabetizadores. E assim era feito.

No quarto ano do curso já fazíamos estágios de regência e voltávamos para a escola para as disciplinas pedagógicas e algumas do currículo comum que eram deixadas para esse momento com vistas aos vestibulares. Nesse momento do curso a apresentação de concursos públicos e possibilidades de ingresso na carreira também eram constantes.

Um ponto muito marcante no curso do CEFAM de São Miguel Paulista foram as visitas técnicas ou excursões como se chamava à época. Muitos passeios culturais, aulas na cidade, eventos, feiras e seminários.

Lembro de ouvir o Prof. Marcio Pochmann pela primeira vez num seminário na Secretaria da Fazenda do Estado de São Paulo num evento organizado pelo professor de Geografia quando estávamos no segundo ano do curso.

Viagens para Barra Bonita, nascente do rio Tietê, exposições de arte na cidade e bienal do livro eram comuns no cotidiano das aulas. Há muitas exposições no MASP, Pinacoteca e os mais variados museus da cidade. O estímulo ao conhecimento e ampliação do repertório cultural fazia parte do nosso currículo no CEFAM.

Aos dezesseis e dezessete anos de idade o CEFAM criava em nós uma redoma de proteção. Era escola de tempo integral com uma bolsa que garantia a permanência no curso e a clareza do objetivo da escola que nos dava muita segurança para o aprofundamento dos estudos e para o amadurecimento na adolescência.

Mais que um currículo bem estruturado, o CEFAM funcionava como nossa segunda casa. Passávamos 10 horas por dia em convívio com colegas e professores, construímos vínculos de afeto e experimentamos muitas histórias. Conflitos, amores, afetos e desafetos, sonhos revolucionários e muitos medos e incertezas.

Ao final do quarto ano do magistério, a prefeitura de São Paulo abriu concurso público para ingresso. Lembro de usar o dinheiro que recebia da bolsa de estudos para pagar a inscrição, fomos em grupo pagar a taxa no banco.

Cheios de dúvidas sobre a faculdade que seguiríamos, sobre as possibilidades de trabalho que nos esperava e também cheios de esperanças sobre o término do curso. Assim fizemos a prova do concurso.

Sem nenhuma experiência, praticamente toda a turma passou. No dia da escolha de vaga encontramos muita gente querida da turma e de turmas anteriores. 
Ingressei no município de São Paulo nas primeiras chamadas e comecei a lecionar numa escola muito próxima da casa em que meus pais moravam.

\section{O INÍCIO DO EXERCÍCIO DO MAGISTÉRIO}

Entre o término do curso do CEFAM e a chamada para assumir o cargo na Prefeitura de São Paulo decorreram longos oito meses. Nesse ínterim dei aulas particulares em casa e comecei a lecionar como professor eventual na escola estadual chamada Neydy de Campos Melges na periferia do Itaim Paulista e divisa com Ferraz de Vasconcelos.

Em meados de 2001 as escolas particulares dificilmente contratavam professores homens para os anos iniciais, sendo assim aos dezessete anos minhas chances de emprego fora do setor público eram diminutas, quase nulas. Entreguei muitos currículos e cheguei a ser chamado por uma escola privada do bairro para ser inspetor de alunos, recusei, pois, eu tinha clareza que queria lecionar.

Ingressei no curso de História assim que concluí o magistério, então cursava a faculdade enquanto trabalhava como professor eventual e particular com aulas de reforço para crianças do bairro.

Ao ser chamado no concurso do Município de São Paulo escolhi uma escola na região em que moravam e fiquei por menos de um mês na EMEF Sem. José Ermírio de Moraes até ser transferido para a EMEF Virgílio de Mello Franco, manteve as aulas como professor eventual no estado com o acúmulo de cargo na prefeitura e estudava no período da noite.

Foi nesse tempo da carreira que aprendi a ser professor.

Ninguém da minha família teve trajetória na Educação, meu pai foi metalúrgico e segurança e minha mãe enfermeira. Não tinham como me orientar sobre os ritos das atribuições de aula, ou mesmo sobre os desafios das escolhas de escola e jornadas de trabalho. No início da carreira tive alguns amigos da comunidade religiosa que frequentava que me deram conselhos preciosos de qual caminho seguir. E foram esses conselhos que segui.

Professor Marcelo Ferreira e Professora Vanessa Silva, ele formado em história me orientou e me inspirou para escolher o mesmo curso, pois sabendo da minha vontade em cursar Ciências Sociais, me alertou sobre o número pequeno de aulas na rede 
estadual. A Vanessa, professora de Língua Portuguesa e esposa do Marcelo, me deu valiosos conselhos sobre os processos de atribuição na prefeitura e no estado. Sempre generosos me socorreram muitas vezes quando precisava de ajuda para tomar decisões, inclusive financeiramente.

Nesse período, na ocasião do concurso do Estado de São Paulo, eu estava inscrito para prestar a prova. No entanto, sem dinheiro também me inscrevi para trabalhar como fiscal na aplicação do concurso. Não prestaria a prova do concurso para trabalhar. Os dois amigos, Marcelo e Vanessa, ao descobrirem isso na véspera do certame, me ofereceram o dinheiro que receberia pelo dia do trabalho e exigiram que eu fosse prestar o concurso. Tomei um sermão deles.

Orgulhoso, nessa ocasião, não aceitei ajuda financeira e fui fazer a prova. Meu número de acertos nas questões objetivas foi muito alto e gabaritei a dissertativa. Me efetivei na rede estadual na primeira chamada do concurso. Foi a aprovação nesse cargo que me possibilitou ingressar no mestrado posteriormente, no programa chamado Bolsa Mestrado.

Os primeiros cinco anos da minha carreira profissional se deu concomitantemente a minha formação universitária. Enquanto fazia História lecionava na Prefeitura e no Estado. Esse tempo foi muito marcante na minha trajetória.

Na EMEF Virgílio de Mello Franco, fui acolhido com muito carinho pelo grupo experiente de professoras. Me ensinaram muito. Eram pacientes com os meus afãs sindicais e revolucionários e generosos no convívio.

Um grupo dessas professoras já estavam na rede municipal a muito tempo e costumavam brincar comigo que o Secretário de Educação delas tinha sido o Paulo Freire. Talvez elas não tenham a dimensão do quanto esse processo de acolhimento e estímulo fez bem para minha formação profissional.

Um ponto muito importante nesse período e que vale ser lembrado, é que nesse tempo a Prefeitura de São Paulo aceitava como parte da pontuação para o processo de evolução funcional os comprovantes de aprovações em concursos públicos. As professoras que me acolheram eram profissionais sábias, engajadas politicamente e leitoras das bibliografias dos concursos. O cotidiano dessa escola que iniciei minha carreira era marcado por debates sobre legislação, conceitos teóricos e metodológicos. Isso contribuiu muito para que eu continuasse aprendendo, prestando concursos e obtendo êxito nas aprovações. 
Do mesmo modo, ao terminar o curso de História, ainda muito jovem com 21 anos, foram essas professoras que me aconselharam fazer Pedagogia e por meio delas que conheci a Fundação Escola de Sociologia e Política que cursei a especialização ao mesmo tempo que fazia Pedagogia.

Esse trajeto faz sentido na compreensão da importância da política pública educacional, pois minha formação e trajetória profissional passam invariavelmente pela ação do estado. No processo de formação como estudante do magistério em escola pública e no ingresso na carreira por meio de concurso público no município e no estado. As duas principais marcas de trajetória só foram possíveis em razão da ação de políticas do estado.

\section{UM BREVE CONTEXTO HISTÓRICO DE CRIAÇÃO DO CEFAM.}

Para compreender a minha trajetória profissional - e parte da trajetória de uma geração de professores formados pelo CEFAM - e para entender as experiências vividas como professor no início da carreira é fundamental que façamos um recorte histórico sobre o contexto de criação do CEFAM.

A história da minha trajetória de formação e início da profissionalização só pode ser lida por meio do entendimento e conhecimento histórico das decisões políticas das décadas anteriores. A ação do estado foram marcos para minha escolarização, profissionalização, ingresso e permanência da carreira docente.

O Centro Específico de Formação e Aperfeiçoamento para o Magistério CEFAM foi um projeto criado na esteira do esvaziamento e das críticas sobre a lei 5692/71 que criava as Habilitações Específicas para o Magistério que desmontaram a o Curso Normal e toda historicidade e identidade já construída em décadas anteriores.

Conforme afirma Tanuri (2000, p. 80):

A lei 5692/71 que estabeleceu diretrizes e bases para o primeiro e o segundo grau, transformou-o numa das habilitações deste nível de ensino, abolindo de vez a profissionalização antes ministrada em escola de nível ginasial. Assim a tradicional escola normal perdia o "status" de nível de escola e, mesmo, de curso, diluindo-se em uma das muitas habilitações profissionais do ensino de segundo grau, a chamada Habilitação Específica para o Magistério (HEM). 
O final dos anos de 1970 e início dos anos de 1980 juntamente com a crescente tentativa de criar movimentos de resistência diante da ditadura militar que cercear as liberdades em todos os setores da sociedade e na Educação, os debates sobre as estruturas e o funcionamento das escolas em geral e nos cursos profissionalizantes de magistério especificamente sofriam a influência deste contexto político com o objetivo de resistir e garantir formação autônoma para os professores.

É nesse contexto que o I Plano Setorial de Educação é pensado em São Paulo, no entanto, apenas no II Plano Setorial de Educação conforme afirma Cavalcante (1994) que se estabelece como objetivo geral a universalização da educação primária:

Esse plano estabeleceu como objetivo geral, para o ensino de $1^{\circ}$ grau, a universalização progressiva, definindo como meta, até 1980, a escolarização de $90 \%$ da faixa etária de 7 a 14 anos (CAVALCANTE, 1994, p. 52).

É a partir destas definições estabelecidas na política institucional que começa a implementação de um projeto de formação de professores, no sentido de revitalizar as Escolas Normais, para capacitar melhor o docente que executaria tal projeto.

Nos anos 1980, com a abertura política e a evidência do fim do governo militar, junto com os movimentos de resistência e reivindicações crescem também as discussões sobre os processos de redemocratização e os desdobramentos desses debates ajudam a compor os pilares para a construção da "nova escola brasileira".

É elaborado, então, segundo Tanuri (2000), o III Plano Setorial da Educação, que compreende o período de 1980 a 1985 e que mantêm o objetivo de valorização dos recursos humanos para o magistério, estabelecendo a Educação Básica como prioridade no processo de desenvolvimento da sociedade e contemplando, ainda, as áreas rurais e as periferias urbanas.

Tendo em vista as duras críticas à formação docente, o CENAFOR, em 1986, publica documento que sintetiza a crítica no período acerca das HEMs (TANURI, 2000, p. 22):

Dispersa no meio de tantas outras, a habilitação ao magistério assumiu caráter propedêutico e descaracterizou-se: se antes de 1971 o curso era acusado de hipertrofiar os aspectos instrumentais, em detrimento do conteúdo básico, geral e específico. O magistério continua entre as habilitações fracas em conteúdo científico, ao mesmo tempo que abriu mão de suas antigas exigências de seus aspectos instrumentais. A antiga 
sistemática do magistério primário em escolas normais foi destruída, e, em seu lugar, nasceu um padrão em quase tudo incompetente. A Habilitação para o Magistério não forma nem para aquilo que seria minimamente necessário ao professor da escola elementar: a capacidade de ensinar a ler, escrever e calcular.

Além destas críticas existia o debate sobre a dicotomização da formação docente, no que se referia à evidente separação entre teoria e prática, o conteúdo e o método, o núcleo comum e o profissionalizante, o desprestígio social do curso, a inadequação dos docentes. Entre essas críticas destacava-se, sobretudo, a ineficiência das aulas de estágio, que não oportunizam vivência de regência para o aluno-professor como expresso nas palavras de Tanuri (2000):

Aos problemas pertinentes a realização de Estágio de prática de ensino. A esse respeito, apesar de toda proclamação a respeito da função integradora da Prática de Ensino e das prescrições legais no sentido de que ela inclusive a observação, a participação e a regência, eram comuns as referências de que os estágios em geral se restringiam a observação e de que vinham sendo cumpridos apenas formalmente (TANURI, 2000, p. 82).

Após inúmeras reuniões entre técnicos do MEC, representantes das Secretarias de Educação dos Estados, bem como educadores, constrói-se um movimento em âmbito federal e estadual, com discussão de projetos, pesquisas e propostas de ação, frequentemente denominados de "revitalização do ensino normal" Tanuri (2000). Entre essas propostas destaca-se a referente ao projeto dos Centros de Formação e Aperfeiçoamento para o Magistério - CEFAM.

Para Tanuri (2000), o projeto criado em 1982 pela antiga Coordenadoria do Ensino Regular de Segundo Grau do MEC tinha por objetivo redimensionar as escolas normais, dotá-las de condições adequadas à formação de profissionais com competência técnica e política e ampliar as funções, de modo torná-las um centro de formação inicial e continuada para professores de educação pré-escolar e para o ensino das séries iniciais

Para os envolvidos neste projeto fica definido que os estados interessados em executar as propostas do MEC para uma alternativa aos cursos de magistério contariam com suporte técnico e financeiro. Os primeiros estados a declarar interesse e participar foram: Alagoas, Minas Gerais e Rio Grande do Sul. Devido à boa repercussão do projeto, logo foram seguidos pelos Estados da Bahia, Pernambuco e Piauí. E assim inicia o Projeto CEFAM em 06 estados brasileiros, com um total de 55 unidades. 
Em 1987, por intermédio do projeto de "Consolidação e Expansão dos CEFAMs" os Centros foram estendidos a mais nove estados: Santa Catarina, Mato Grosso, Mato Grosso do Sul, Sergipe, Paraíba, Rio Grande do Norte, Pará, Goiás e São Paulo, de modo a atingir 120 unidades em 1987, com 72.914 matrículas (Tanuri, 2000).

\section{A IMPLANTAÇÃO DO CEFAM NO ESTADO DE SÃO PAULO}

Em São Paulo a implantação do CEFAM assumiu características diferenciadas dos demais estados, pois o compromisso de criar orçamento destinado a remuneração dos estudantes por meio de bolsa de estudos no valor de 1 salário mínimo vigente deu ao projeto grande visibilidade e procura. Essa decisão caminhava na mesma direção de atender os estudantes das camadas populares e moradores das periferias urbanas e rurais, como (Moreira, 2008, p. 31) afirma em sua pesquisa:

Considerando que o ensino era integral e que os alunos eram, obrigatoriamente, $95 \%$ oriundos de escolas públicas a bolsa de estudos fez com que o Projeto assumisse grande visibilidade, além de garantir a permanência, em regime integral do aluno, possibilitando o aprofundamento teórico - prático e garantido os estágios.

O advento da bolsa de estudos elevou a procura a ponto de necessitar de realização de provas para seleção de ingresso. Essas provas também trouxeram os alunos com melhor preparo do ensino fundamental, colaborando assim com o projeto de formação de exigência elevada na rotina dos estudantes que também permaneciam na escola em período integral.

O decreto do Governo do Estado de São Paulo n. 28.089, de 13 de janeiro de 1988 expressa claramente os objetivos e finalidades na criação do CEFAM paulista.

Considerando-se:

A necessidade de recuperar a especificidade da formação do professor das séries iniciais do ensino de primeiro grau e da pré-escola;

A importância da Habilitação específica para o Magistério na formação integral do professor;

A necessidade de garantir a efetiva realização do estágio ao longo do curso de Habilitação para o Magistério;

A necessidade de se garantir a melhoria da qualidade do ensino através do aperfeiçoamento constante do pessoal docente;

Artigo $1^{\circ}$ - Ficam criados na rede estadual de ensino os Centros Específicos de Formação e Aperfeiçoamento para o Magistério com a finalidade de: 
I - Dar prioridade na efetiva formação dos professores da pré-escola até a $4^{\circ}$ série do $1^{\circ} \mathrm{Grau}$;

II - Aprimorar a formação dos professores que atuam na Habilitação Específica de $2^{\circ}$ Grau para o magistério e nas classes da pré-escola até a $4^{\circ}$ série do $1^{\circ} \mathrm{Grau}$.

Artigo $4^{\circ}$ - Serão concedidas bolsas de estudos a alunos do Centro na forma a ser regulamentada.

O CEFAM de São Paulo torna-se, assim, referência na formação de professores a partir do reconhecimento de sua experiência como bem sucedida, pela própria comunidade acadêmica.

Exemplo disso está na recomendação feita em documento do IV Congresso Estadual Paulista de Formação de Educadores, realizado em 1996, na cidade de Águas de São Pedro-SP, pelo Grupo de Trabalho de Formação de Educadores para séries iniciais. Nesse documento, no item que concerne à indicação de instituição para formar professores há a indicação explícita:

O grupo conclui que essa formação do professor reflexivo só ocorrerá em Centros de Formação Específicos que assegurem as condições já assinaladas. Assim propõe que, a partir da avaliação e discussão de experiências bem sucedidas, tanto no $2^{\circ}$ grau - CEFAM - quanto no $3^{\circ}$ grau - Pedagogia - os Centros incorporem os sucessos obtidos por essas experiências, ampliando-as (ÁGUAS DE SÃO PEDRO, IV CEPFE, p. 2).

Muito embora o CEFAM em São Paulo tenha obtido sucesso inquestionável, também sofreu críticas no que se referia à formação dos professores que atuavam nos Centros, bem como quanto ao acompanhamento e aproveitamento de egressos pela rede pública de ensino.

Ainda assim foram acrescentadas condições já reivindicadas há muito tempo pelos educadores, tais como: a presença de um coordenador pedagógico por unidade de CEFAM, o pagamento de horas de trabalho pedagógico e horas atividades aos professores, bem como maiores investimentos em recursos materiais e didáticos. Também a respeito do CEFAM de São Paulo, Gatti (2000) o define como sendo uma iniciativa de grande porte na direção de introduzir um diferencial nessa formação.

Os cursos oferecidos no CEFAM de São Paulo, mesmo possuindo lacunas e necessidade de melhorias demonstram que as avaliações procedidas sobre seu desempenho mostram muito mais aspectos positivos do que negativos. Nas palavras de Gatti (2000): “(...) É uma proposta que tem suas qualidades reafirmadas”. 


\section{CONSIDERAÇÕES FINAIS}

Ao revisitar a própria trajetória de formação e início da profissionalização alguns pontos coloco em destaque.

Os três primeiros estão na perspectiva do próprio percurso de vida.

- $\quad$ O apoio familiar e o fato de encontrar bons professores no caminho foi essencial para escolha e permanência da escola de magistério e depois na universidade.

- $\quad \mathrm{O}$ encontro com amigos profissionais da educação que sempre foram generosos em bons conselhos sobre a carreira e os desafios enfrentados no cotidiano também se tornaram marcas importantes nesse processo.

- O CEFAM foi um divisor de história na minha vida, a possibilidade de estudar naquela escola, marcou todas as minhas escolhas de vida posteriormente. A carreira docente, foi para mim a única possibilidade de trabalho e cidadania. Foi a base para a construção sobre as escolhas políticas e ideológicas e foi o que me forjou como homem e profissional da Educação.

Os outros três pontos de destaque estão na perspectiva da ação do estado.

- A geração de professores formada no CEFAM é conhecidamente uma geração de bons profissionais. Além dos resultados da pesquisa de mestrado que realizei em 2008 no Programa de Estudos Pós Graduados em Educação: História, Política e Sociedade na PUC SP sobre a trajetória dos egressos do CEFAM, podemos afirmar que as memórias sobre esse modelo de escola são, sobretudo, de sucesso do modelo de formação.

- $\quad$ O estado é o principal indutor de políticas educacionais que transformam a vida de jovens. A manutenção de modelos de formação profissional com apoio integral para a permanência de jovens na escola é fundamental e transformador na história de vida da juventude.

- $\quad \mathrm{Na}$ área da educação, os concursos de ingresso e as condições de permanência da carreira, também são elementos essenciais para o atendimento da população e valorização dos profissionais. Foram por meio de concursos públicos que minha carreira na educação foi possível. Essa deve ser uma bandeira de permanente vigilância dos profissionais da educação e da sociedade. 
Na minha defesa de mestrado, a banca me perguntou sobre o que eu era ao terminar o curso de magistério no CEFAM.

Minha resposta foi: "Eu saí do CEFAM sem saber ser outra coisa, senão professor”. E assim tem sido desde lá.

\section{REFERÊNCIAS}

CAVALCANTE, M. J. A escola Normal caminhos e descaminhos, um novo itinerário. In: CEFAM: uma alternativa pedagógica para a formação do professor. São Paulo: Cortez, 1994.

DOCUMENTO FINAL do GT. Formação de Educadores para as séries iniciais. IV Congresso Estadual Paulista de Formação de Educadores. Águas de São Pedro. 1996.

GATTI, B. A. Formação de Professores e carreira: problemas e movimentos de renovação. Campinas, SP: Autores Associados, 2000.

MOREIRA, D. A Trajetória de formação e profissionalização dos egressos do CEFAM de São Miguel Paulista. Pesquisa de Mestrado. EHPS- PUC. 2008.

SÃO PAULO. ESTADO 1997. Lei Complementar nº 836/97. Dispõe sobre o plano de carreira docente.

SÃO PAULO. ESTADO 1988. Decreto n 28.089. Dispõe sobre a criação dos Centros Específicos de Formação e Aperfeiçoamento para o Magistério.

SÃO PAULO. ESTADO 1988. Resolução da Secretaria Estadual de Educação. Nº14/88. Dispõe sobre a regulamentação para a instalação do CEFAM.

SÃO PAULO. ESTADO 1987. Parecer do Conselho Estadual de Educação n³0/87. Dispõe sobre a organização de pessoal e corpo docente para o CEFAMs.

SÃO PAULO. ESTADO 1988. Parecer do Conselho Estadual de Educação no 352/88. Dispõe sobre a articulação dos currículos de base comum e de formação específica para o magistério.

TANURI, L. história da formação de professores. Revista Brasileira de Educação, Rio de Janeiro/Campinas: ANPEd-UERJ/A. Associados, n.14, maio-agosto/2000, p.61-88. 